\title{
Discovery Learning : Penerapan dalam pembelajaran IPA berbantuan bahan ajar digital interaktif untuk meningkatkan prestasi belajar siswa
}

\author{
Ngulmi Khamidah $^{1}$, Winarto ${ }^{2}$, Vita Ria Mustikasari ${ }^{3 *}$ \\ Pendidikan IPA $^{13}$, Fisika ${ }^{2}$, FMIPA, Universitas Negeri Malang, Malang, Jawa Timur, Indonesia \\ *Corresponding author email: vita.ria.fmipa@um.ac.id
}

\section{Artikel info}

Received : 28 Januari 2019

Revised : 11 April 2019

Accepted : 19 April 2019

Kata kunci:

Bahan ajar digital interaktif Model discovery learning Prestasi belajar

\begin{abstract}
ABSTRAK
Penggunaan bahan ajar dalam pembelajaran IPA sangat penting karena dapat meningkatkan efektivitas dalam peningkatan hasil belajar siswa. Penelitian ini bertujuan untuk mengetahui adanya pengaruh penggunaan bahan ajar digital interaktif dalam pembelajaran IPA dengan model discovery learning terhadap prestasi belajar siswa kelas VIII MTsN 3 Ponorogo. Penelitian quasi-eksperimen ini menggunakan posttest-only group design. Pengambilan sampel menggunakan teknik purposive sampling. Hasil penelitian ini menunjukkan bahwa ada pengaruh yang signifikan dari penerapan bahan ajar digital interaktif dengan model discovery learning terhadap prestasi belajar siswa. Dengan demikian, penggunaan bahan ajar digital interaktif dengan model discovery learning bisa digunakan oleh guru untuk mengakomodasi kemampuan kognitif siswa sehingga prestasi belajar siswa dapat meningkat.
\end{abstract}

\section{ABSTRACT}

Keywords:
Interactive digital
teaching materials
Discovery learning
models

Learning achievements

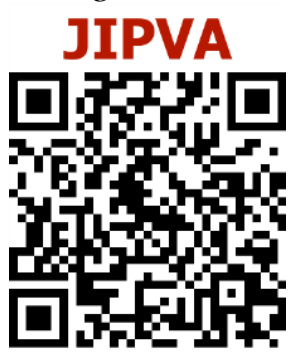

Discovery Learning : The Application of digital interaktif teaching materials in Sciences learning to improve students's learning achievement. The use of interactive digital teaching materials in learning can improve efficiency and effectiveness because abstract material can be visualized so that it affects learning achievement. This study aims to determine the effect of the use of interactive digital teaching materials in science learning with discovery learning models on the learning achievement of class VIII students of MTsN 3 Ponorogo. This type of research is quasi-experimental. The research design used was posttestonly group design. The results of this study indicate that the value of tcount $>$ t table is 5.14> 2.01, the null hypothesis is rejected and the alternative hypothesis is accepted. Based on the results of the study it was concluded that the use of interactive teaching materials with discovery $l$ learning models had a positive effect on class VIII student achievement.

https://doi.org/10.31331/jipva.v3i1.770

How to Cite : Khamidah, N., Winarto, Mustikasari, V.R. (2019). Discovery Learning : Penerapan dalam pembelajaran IPA berbantuan bahan ajar digital interaktif untuk meningkatkan prestasi belajar siswa. JIPVA (Jurnal Pendidikan IPA Veteran), 3(1), 87-99. doi:https://doi.org/10.31331/jipva.v3i1.770

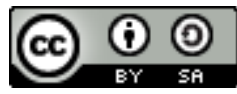




\section{PENDAHULUAN}

Prinsip pembelajaran IPA berdasarkan Permendikbud No. 22 Tahun 2016 tentang standar proses pendidikan dasar dan menengah, pembelajaran disarankan memanfaatkan teknologi informasi dan komunikasi untuk meningkatkan efisiensi dan efektivitas pembelajaran (Kementerian Pendidikan dan Kebudayaan, 2016). Teknologi informasi dan komunikasi tersebut dapat berupa media pembelajaran. Menurut Ramadhani, Mulyani, dan Utomo (2016) media pembelajaran dapat melatih siswa untuk belajar secara mandiri dan memotivasi untuk mengevaluasi materi yang telah disampaikan oleh guru, media pembelajaran mampu memberikan feedback kepada penggunanya sehingga kekurangan dalam memahami materi bisa diatasi. Beberapa penelitian menunjukkan bahwa media sangat berperan dalam pencapaian tujuan belajar siswa (Anjarwati, Winarno, \& Churiyah, 2016; Lin \& Wu, 2016; Oyedele, Rwambiwa, \& Mamvuto, 2013; Purwono, Yutmini, \& Anitah, 2014).

Media pembelajaran sangat dibutuhkan bagi siswa agar mereka dapat mengeksplorasi lingkungan sekitarnya sehingga pembelajaran yang bersifat teoritis dapat lebih realistis (Widiyawati, 2017). Komputer sebagai media pembelajaran mempunyai efektivitas yang cukup tinggi karena mampu menggabungkan dan menghadirkan teks, grafik, audio, gambar bergerak (video dan animasi) dengan menggabungkan link dan tool yang memungkinkan pemakai melakukan navigasi, berinteraksi, berkreasi, dan berkomunikasi dalam waktu dan tempat yang sama (Anwariningsih \& Ernawati, 2013; Firdaus, Damiri, \& Tresnawati, 2012). Pemanfaatan komputer dalam media pembelajaran dapat menyediakan materi yang representatif, sehingga dapat menumbuhkan motivasi belajar siswa. Namun demikian tidak semua materi pembelajaran dapat disampaikan dengan metode yang sama. Seperti halnya pada materi pembelajaran IPA yang mempunyai karakteristik masing-masing dalam penyajiannya.

Materi pada pelajaran IPA yang dianggap sulit oleh sebagian siswa untuk dipahami adalah materi cahaya dan alat optik (Suradnya, Suyanto, \& Suana, 2016; Hayati, Budi, \& Handoko, 2015). Materi cahaya terdiri dari beberapa materi yang tidak dapat diamati secara langsung seperti proses pembentukan bayangan, sehingga siswa sulit untuk memahami konsep tersebut. Siswa menggunakan imajinasi untuk dapat lebih memperdalam pengetahuannya, contohnya untuk melihat jalannya cahaya dalam proses pembentukan bayangan, sehingga dibutuhkan media pembelajaran berupa bahan ajar yang tidak hanya buku teks saja, tetapi dari berbagai sumber yang lain seperti teknologi informasi dan komunikasi yang dapat diakses kapan saja (Harsono, Soesanto, \& Samsudi, 2009). Salah satu media pembelajaran yang dapat membantu proses visualisasi dan memecahkan masalah tersebut adalah bahan ajar digital interaktif. Pengembangan media pembelajaran multimedia interaktif memfasilitasi belajar siswa dalam memecahkan masalah (Wardani, Mudzalipah, \& Hidayat, 2013). Penggunaan bahan ajar digital interaktif dalam pembelajaran membuat siswa tertarik dalam pembelajaran dikarenakan adanya visualisasi yang dapat mendorong siswa untuk memahami materi yang diberikan (Sutarno, 2011).

Penggunaan bahan ajar digital interaktif sesuai dengan Kurikulum 2013 yang menuntut guru menggunakan teknologi informasi dan komunikasi dalam pembelajaran. Menurut Hayati, Budi, dan Handoko (2015) penggunaan bahan ajar pada materi fisika dapat meningkatkan hasil belajar siswa. Menurut Suradnya, Suyanto, dan Suana, (2016) Bahan ajar 
digital interaktif dapat membantu siswa dalam memahami konsep-konsep yang tidak dapat divisualisasikan seperti pada materi cahaya dan alat optik, sehingga dapat menjadi pendukung dalam proses pembelajaran di kelas maupun sebagai sarana belajar mandiri oleh siswa. Bahan ajar ini dapat memberikan kemudahan siswa memahami konsep abstrak pada materi cahaya dan alat optik serta memperoleh hasil belajar yang lebih maksimal. Penggunaan multimedia interaktif memberikan dampak postif terhadap penguasaan konsep siswa dalam pembelajaran (Gunawan, Harjono, \& Sutrio, 2015; Husein, Herayanti, \& Gunawan, 2015).

Beberapa penelitian lain juga menunjukkan bahwa penggunaan video dalam pembelajaran berdampak positif serta dapat meningkatkan hasil belajar siswa (Izzudin, Masugino, \& Suharmanto, 2013 ; Busyaeri, Udin, \& Zaenuddin, 2016; Iwantara, Sadia, \& Suma, 2014; Fadhashar, Indriyanti, \& Lisdiana, 2017). Penggunaan video sebagai media pembelajaran dapat meningkatkan motivasi belajar siswa karena dengan video materi yang abstrak dapat lebih nyata dan dapat diamati dengan baik. Dengan motivasi belajar yang tinggi siswa tidak perlu dipaksa untuk berpikir. Siswa menikmati proses pembelajaran yang menarik sehingga tingkat berpikir siswa akan semakin berkembang. Tingkat berpikir siswa harus terus dikembangkan sehingga siswa dapat mencapai kemampuan berpikir tingkat tinggi (Nurwahidah, 2018). Kemampuan berpikir tingkat tinggi sesuai dengan tujuan pembelajaran yang ada pada Kurikulum 2013. Pembelajaran dengan menggunakan media pembelajaran menghasilkan rata-rata lebih baik dibandingkan dengan menggunakan media ceramah konvensional (Harsono et al., 2009).

Selain media pembelajaran yang mendukung, guru juga harus memilih model pembelajaran yang efektif dalam memberdayakan kompetensi siswa. Druckman dan Ebner (2017) menyatakan bahwa discovery learning membuat pembelajaran lebih efektif sehingga dapat meningkatkan pemahaman konsep siswa. Hayati dan Berlianti, (2016) menyatakan bahwa pembelajaran discovery dapat meningkatkan aktivitas dan hasil belajar. Dewi, Nurmilawati, dan Budiretnani, (2017) juga menyatakan bahwa pembelajaran discovery dapat meningkatkan literasi sains siswa. Dengan demikian mengkombinasikan bahan ajar digital interaktif dengan menggunakan model discovery learning diharapkan mampu membantu siswa dalam mencapai prestasi belajar yang maksimal.

Penelitian-penelitian sebelumnya menyatakan bahwa bahan ajar digital interaktif dan discovery learning dapat meningkatkan hasil belajar siswa (Hayati, Bintari, \& Sukaesih, 2018; Supriyanto, 2014). Hasil penelitian Hakim dan Windayana, (2016) menunjukkan bahwa penggunaan multimedia interaktif dapat meningkatkan hasil belajar matematika siswa SD. Hasil penelitian Kurniawati dan Nita, (2018) menunjukkan bahwa media pembelajaran berbasis multimedia interaktif dapat meningkatkan pemahaman konsep mahasiswa. Hasil penelitian Supriyanto, (2014) menunjukkan discovery learning meningkatkan hasil belajar siswa. Hasil penelitian Fitri dan Derlina, (2015) menunjukkan pembelajaran discovery learning berpengaruh pada hasil belajar siswa materi suhu dan kalor. Peneliti terdahulu masih mengalami hambatan dalam pembelajaran dengan menggunakan discovey learning, yang pertama dalam desain tampilan media yang kreatif masih perlu dilakukan agar siswa tidak merasa cepat jenuh serta untuk meningkatkan daya nalar dan imajinasi siswa dalam proses pembelajaran (Hayati et al., 2018). Kedua, dalam pembelajaran discovery learning siswa 
masih kurang dilibatkan dalam berpikir kreatif dan kurang aktif serta guru belum bisa mengatur waktu dengan baik agar pembelajaran dapat efektif dengan waktu yang tersedia relatif singkat. Berdasarkan uraian tersebut diperlukan inovasi dalam pembelajaran menggunakan bahan ajar digital interaktif dan discovery learning. Kebaharuan dari penelitian ini adalah penggunaan bahan ajar digital interaktif dengan model discovery learning untuk meningkatkan hasil belajar siswa dengan waktu yang relatif singkat serta membuat siswa lebih aktif di dalam pembelajaran. Tujuan penelitian ini adalah untuk mengetahui pengaruh penggunaan bahan ajar digital interaktif dengan model discovery learning terhadap peningkatan prestasi belajar siswa MTsN 3 Ponorogo kelas VIII.

\section{METODE}

\section{Jenis Penelitian}

Jenis penelitian ini adalah penelitian quasi-experiment dan menggunakan posttest-only group design. Desain ini dilaksanakan untuk menyelidiki pengaruh penggunaan bahan ajar digital interaktif dalam pembelajaran IPA dengan model discovery learning terhadap prestasi belajar siswa sesuai dengan Tabel 1 .

Tabel 1. Desain posttest-only group design

\begin{tabular}{ccc}
\hline Kelas & Perlakuan & Posttest \\
\hline Eksperimen & $\mathrm{X}_{1}$ & $\mathrm{O}$ \\
\hline Kontrol & $\mathrm{X}_{2}$ & $\mathrm{O}$ \\
\hline
\end{tabular}

Keterangan :

$\mathrm{X}_{1}$ : Pembelajaran menggunakan bahan ajar digital interaktif

$\mathrm{X}_{2}$ : Pembelajaran tanpa menggunakan bahan ajar digital interaktif

\section{Waktu dan Tempat Penelitian}

Penelitian ini dilakukan pada bulan November 2018. Tempat penelitian yaitu di MTsN 3 Ponorogo.

\section{Target/Subjek Penelitian}

Populasi pada penelitian ini terdiri dari tujuh kelas dengan total 172 siswa. Pengambilan sampel menggunakan teknik purposive sampling di mana siswa memiliki kemampuan awal yang sama untuk dijadikan subjek penelitian. Sampel penelitian ini adalah siswa kelas VIII B dan VIII F di MTsN 3 Ponorogo. Kelas VIII B sebagai kelas eksperimen, sedangkan kelas VIII F sebagai kelas kontrol.

\section{Prosedur}

Tahap awal penelitian ini dilakukan persiapan di antaranya menyiapkan instrumen penelitian berupa silabus, RPP, bahan ajar, dan soal evaluasi. Silabus disusun melalui beberapa langkah, yaitu tahap identifikasi mata pelarajan, perumusan KI dan KD, penentuan materi pokok, pemilihan kegiatan pembelajaran, penentuan indikator, dan penilaian dalam 


\section{Discovery Learning : Penerapan dalam pembelajaran IPA berbantuan bahan ajar digital interaktif untuk meningkatkan prestasi belajar siswa

bentuk instrumen. RPP yang digunakan dalam penelitian dibuat berdasarkan materi pada KD 3.12 kelas VIII tentang cahaya dan alat optik dengan model discovery learning. Bahan ajar yang digunakan adalah bahan ajar digital interaktif. Bahan ajar disusun melalui beberapa langkah, yaitu perancangan bahan ajar dengan melakukan seleksi dan membuat format bahan ajar serta menyusun bahan ajar dengan menggunakan 3D flipbook profesional. Soal evaluasi yang digunakan berupa soal pilihan ganda sejumlah 30 butir soal. Soal evaluasi terlebih dahulu dianalisis dan dipilih melalui validasi empiris dan didukung dengan tingkat kesukaran dan daya pembeda. Berdasarkan validasi empiris, diperoleh soal valid sebanyak 20 soal dan reliabilitas soal adalah 0,765 dengan kriteria reliabilitas tinggi. Berdasarkan analisis yang dilakukan pada 20 soal yang valid, terdapat 6 soal dengan kriteria sukar, 11 soal dengan kriteria sedang, dan 3 soal dengan kriteria mudah.Berdasarkan analisis daya pembeda pada 20 soal yang valid, terdapat 8 soal dengan kriteria baik, 6 soal dengan kriteria cukup, dan 6 soal dengan kriteria jelek. Pada tahap persiapan dilakukan pemilihan kelas eksperimen dan kelas kontrol.

Kemudian dilakukan tahap pelaksanakan yaitu melaksanakan pembelajaran dengan menggunakan bahan ajar digital interaktif untuk kelas eksperimen dan pembelajaran dengan tidak menggunakan bahan ajar digital interaktif untuk kelas kontrol, kemudian melaksanakan evaluasi terhadap prestasi belajar siswa dengan melakukan posttest. Pada tahap akhir dilakukan pengolahan data dan menganalisis data hasil penelitian untuk membuktikan hipotesis penelitian.

\section{Data, Intrumen, dan Teknik Pengumpulan Data}

Kelas eksperimen dan kelas kontrol memiliki kemampuan akademik yang sama. Data yang digunakan adalah data keterlaksanaan pembelajaran, nilai kemampuan awal siswa, dan nilai prestasi belajar siswa. Data keterlaksanaan pembelajaran digunakan untuk mengamati kesesuaian pelaksanaan pembelajaran dengan RPP pada setiap pertemuan. Pengumpulan data keterlaksanaan pembelajaran dilakukan dengan melakukan observasi secara langsung dalam pembelajaran oleh observer. Data kemampuan awal siswa didapatkan dari nilai ujian tengah semester (UTS) ganjil. Data prestasi belajar siswa didapatkan dari nilai posttest menggunakan 20 soal pilihan ganda.

\section{Teknik Analisis Data}

Data nilai kemampuan awal siswa dilakukan uji normalitas dan uji homogenitas. Hasil uji normalitas dengan nilai signifikansi menggunakan uji Kolmogorov-Smirnov kelas eksperimen sebesar 0,117 dan pada kelas kontrol sebesar 0,099. Karena nilai signifikansi kelas eksperimen dan kelas kontrol $D_{\text {hitung }}<D_{\text {tabel }}$ maka hasil tersebut menunjukkan nilai pada kedua kelas terdistribusi secara normal. Hasil uji homogenitas dengan menggunakan uji $\mathrm{F}$ $F_{\text {hitung }}(0,639)<F_{\text {tabel }}(2,01)$ maka dapat disimpulkan bahwa data kemampuan awal kedua kelas homogen. Antara kelas eksperimen dan kelas kontrol memiliki varian yang sama.

Data keterlaksanaan pembelajaran dianalisis dengan menggunakan teknik analisis persentase. Analisis data untuk mengetahui pengaruh penggunaan bahan ajar digital interaktif dalam pembelajaran IPA menggunakan model discovery learning terhadap prestasi belajar siswa yaitu dilakukan uji-t menggunakan independent sample t-test dengan taraf signifikan 
0,05. Kriteria pengambilan keputusan yaitu jika nilai signifikan $<0,05$ atau jika $t_{\text {hitung }}>t_{\text {tabel }}$ maka $\mathrm{H}_{0}$ ditolak dan $\mathrm{H}_{1}$ diterima.

\section{HASIL DAN PEMBAHASAN}

Bahan ajar digital interaktif yang digunakan memuat tentang materi pembelajaran cahaya dan alat optik, video percobaan, soal latihan yang memungkinkan siswa dapat mengisi jawaban pada kolom yang disediakan. Soal dimunculkan setelah tampilan materi atau video percobaan agar siswa membaca materi dan mengamati video terlebih dahulu. Salah satu kelebihan dari bahan ajar digital interaktif ini, selain soal berupa pilihan ada juga soal yang memungkinkan siswa dapat mengetik uraian jawaban pada kolom yang disediakan setelah itu kebenaran jawaban bisa langsung dicek dengan pilihan menu "cek jawaban" di bawahnya. Siswa dapat mengeksplorasi pengetahuannya dan menuangkan dalam kolom jawaban yang disediakan di bawah masing-masing soal pada tiap bahasan. Setelah mengetahui kebenaran jawaban, siswa juga dapat melihat penjelasan yang benar dari pertanyaan tersebut. Dengan begitu bahan ajar yang digunakan lebih interaktif dengan siswa. Tampilan depan bahan ajar digital interaktif yang digunakan terlihat pada Gambar 1.

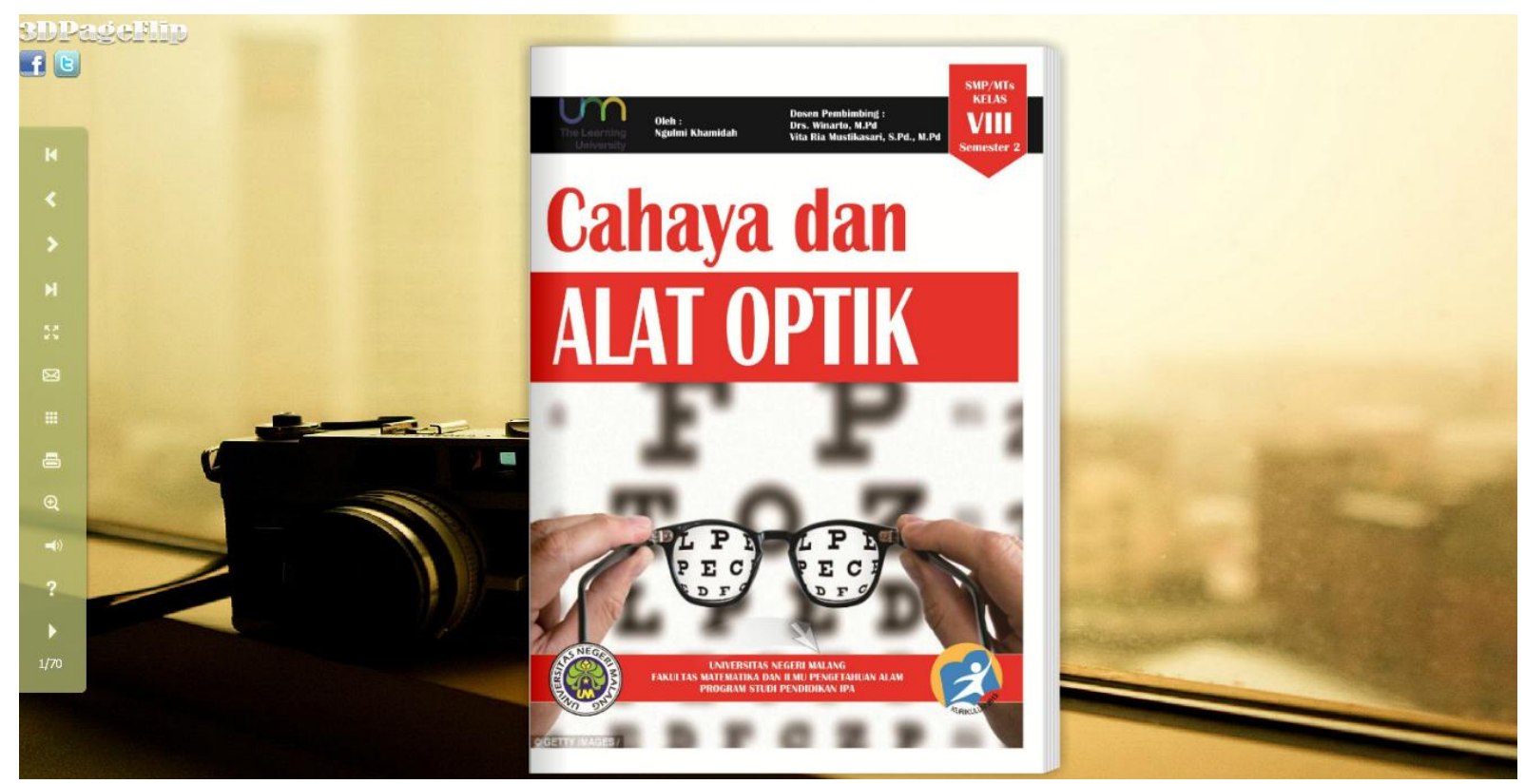

Gambar 1. Halaman depan bahan ajar digital interaktif

Gambar 1 adalah cover dari bahan ajar yang digunakan dalam pembelajaran IPA dengan model discovery learning. Pada halaman depan menampilkan judul materi dan nama penulis. Contoh isi bahan ajar digital interaktif dapat dilihat pada Gambar 2. 


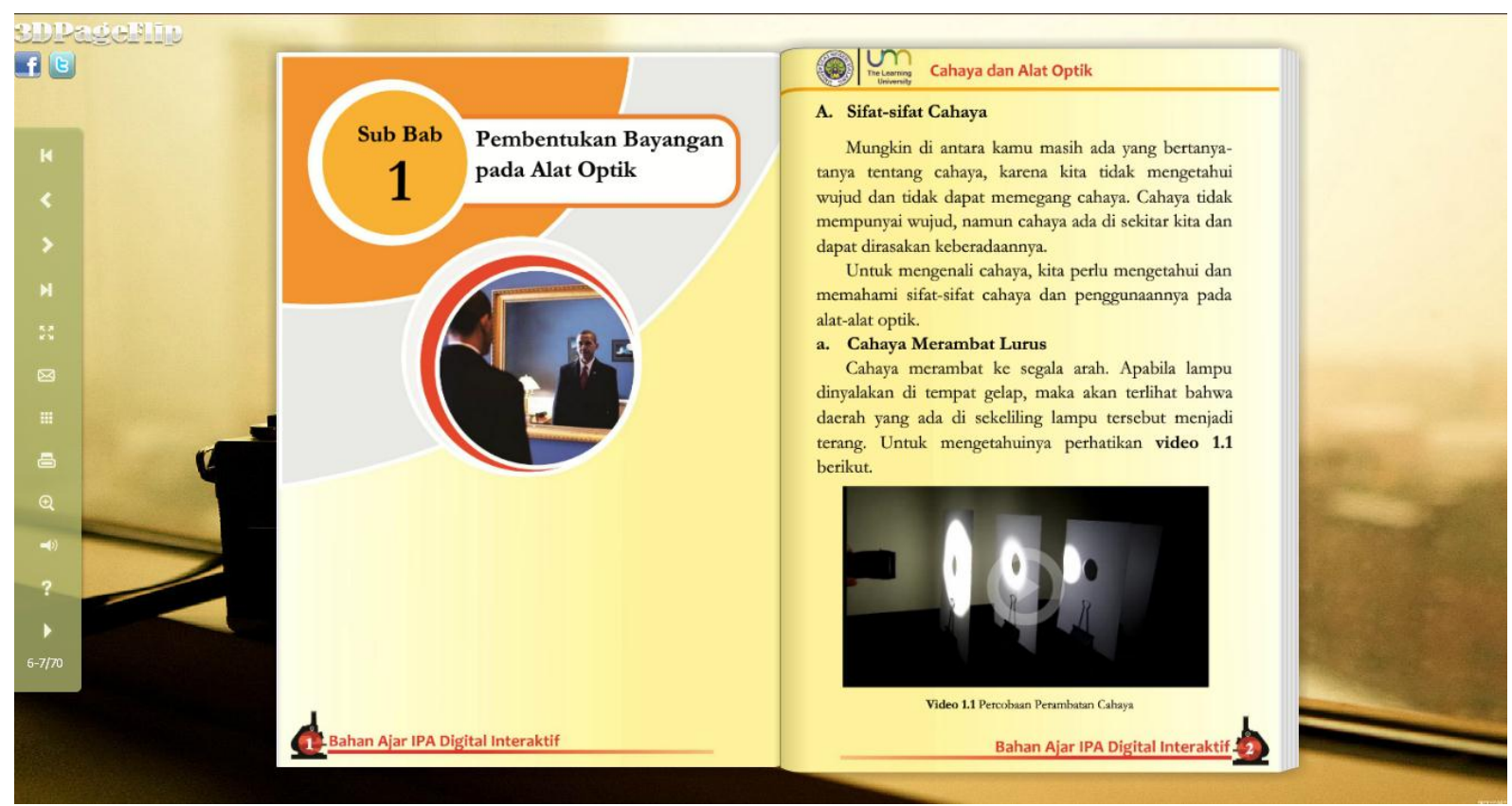

Gambar 2. Contoh isi bahan ajar digital interaktif

Gambar 2 merupakan isi dari bahan ajar digital interaktif yang digunakan dalam pembelajaran IPA dengan model discovery learning. Tidak hanya menampilkan materi berupa tulisan saja tetapi bahan ajar juga menampilkan video-video percobaan sehingga dapat memberikan pengalaman yang lebih nyata kepada mereka sesuai dengan model pembelajaran yang diguankan yaitu discovery learning.

Data prestasi belajar siswa kelas eksperimen dan kelas kontrol yang diperoleh dari nilai posttest disajikan pada Tabel 3. Data nilai posttest ini selanjutnya diuji normalitas dan homogenitas datanya.

Tabel 3. Data posttest prestasi belajar siswa

\begin{tabular}{lcc}
\hline \multicolumn{1}{c}{ Parameter } & Kelas Kontrol & Kelas Eksperimen \\
\hline Jumlah siswa (N) & 24 & 25 \\
Nilai rata-rata (X) & 59,4 & 72,8 \\
Standar deviasi (sd) & 11,732 & 5,605 \\
\hline
\end{tabular}

Berdasarkan Tabel 3 diketahui nilai rata-rata kelas eksperimen adalah 72,8 sedangkan kelas kontrol adalah 59,4. Hal ini menunjukkan bahwa prestasi belajar kemampuan awal kelas eksperimen adalah baik sedangkan prestasi belajar kelas kontrol adalah cukup. Hasil uji normalitas data posttest terlihat pada Tabel 4.

Tabel 4. Hasil uji normalitas data posttest

\begin{tabular}{lccc}
\hline \multicolumn{1}{c}{ Kelas } & D $_{\text {hitung }}$ & D tabel $_{\text {1 }}$ & Kesimpulan \\
\hline Eksperimen & 0,187 & 0,272 & Normal \\
Kontrol & 0,163 & 0,278 & Normal \\
\hline
\end{tabular}

Berdasarkan Tabel 4 diketahui bahwa prestasi belajar kelas eksperimen $\mathrm{D}_{\text {hitung }}(0,187)$ $<D_{\text {tabel }}(0,272)$. Sedangkan untuk kelas kontrol diperoleh $D_{\text {hitung }}(0,163)<D_{\text {tabel }}(0,278)$. 
Berdasarkan hasil uji normalitas menunjukkan bahwa $\mathrm{H}_{0}$ diterima, maka data prestasi belajar kedua kelas terdistribusi secara normal.

Tabel 5. Hasil uji homogenitas data posttest

\begin{tabular}{lllc}
\hline \multicolumn{1}{c}{ Kelas } & $\mathbf{F}_{\text {hitung }}$ & $\mathbf{F}_{\text {tabel }}$ & Kesimpulan \\
\hline $\begin{array}{l}\text { Eksperimen } \\
\text { Kontrol }\end{array}$ & 0,228 & 2,01 & Homogen \\
\hline
\end{tabular}

Berdasarkan Tabel 5 diperoleh prestasi belajar untuk kelas eksperimen dan kelas kontrol $\mathrm{F}_{\text {hitung }}(0,228)<\mathrm{F}_{\text {tabel }}(2,01)$, maka data prestasi belajar kelas eksperimen dan kelas kontrol tersebut homogen.Selanjutnya dilakukan uji kesamaan dua rerata dengan uji-t dua pihak menggunakan independent sample t-test. Hasil uji-t (posttest) disajikan pada Tabel 6.

Tabel 6. Hasil uji-t

\begin{tabular}{|c|c|c|}
\hline Indikator & Eksperimen & Kontrol \\
\hline Jumlah sampel & 25 & 24 \\
\hline Mean & 72,8 & 59,37 \\
\hline Varians & 31,42 & 137,64 \\
\hline$t_{\text {hitung }}$ & & \\
\hline$t_{\text {tabel }}$ & & \\
\hline
\end{tabular}

Tabel 6 menunjukkan bahwa $t_{\text {hitung }}>t_{\text {tabel, }}(5,14)>(2,01)$, maka hipotesis penelitian diterima bahwa penggunaan bahan ajar digital interaktif dalam pembelajaran IPA dengan model discovery learning berpengaruh positif terhadap prestasi belajar siswa kelas VIII MTsN 3 Ponorogo. Bahan ajar digital interaktif dapat membantu dalam proses pembelajaran, dapat digunakan secara mandiri oleh siswa, dan dapat menjelaskan fenomena yang tidak dapat divisualisasikan. Sejalan dengan pernyataan Muhson (2010) bahwa media pembelajaran dapat mengkonkretkan konsep-konsep yang bersifat abstrak, sehingga dapat mengurangi verbalisme. Selanjutnya menurut Viajayani, Radiyono, dan Rahardjo (2013) komputer dapat membuat konsep-konsep yang abstrak menjadi konkret dengan visualisasi stasis maupun dengan visualisasi dinamis (animasi), selain itu komputer dapat membuat suatu konsep lebih menarik sehingga menambah motivasi untuk mempelajari dan memahaminya.

Proses pembelajaran dengan menggunakan bahan ajar digital interaktif membuat siswa lebih tertarik untuk mengikuti pembelajaran. Proses pembelajaran menjadi lebih efektif dan efisien. Beberapa peneliti menyatakan bahwa bahan ajar digital interaktif memudahkan guru dalam menyampaikan materi yang bersifat abstrak dan tidak dapat diamati secara langsung (Anwariningsih \& Ernawati, 2013; Chien, Chen, \& Jeng, 2010; Leow, 2014). Bahan ajar digital interaktif dapat memvisualisasikan materi yang tidak bisa diamati secara langsung seperti jalannya sinar sehingga membuat gambar menjadi hidup. Dengan media pembelajaran akan lebih jelas maknanya sehingga dapat lebih dipahami oleh siswa dan memungkinkan menguasai dan mencapai tujuan pembelajaran (Anjarwati et al., 2016; Lin \& Wu, 2016; Sudjana \& Rivai, 2011). Dengan media pembelajaran, materi yang dipelajari akan lebih jelas dan mudah untuk dipahami oleh siswa, serta memungkinkan siswa menguasai tujuan belajar yang baik (Djamarah \& Zain, 2002). 


\section{Discovery Learning : Penerapan dalam pembelajaran IPA berbantuan bahan ajar digital interaktif untuk meningkatkan prestasi belajar siswa

Hasil analisis data menunjukkan bahwa penggunaan bahan ajar digital interaktif berpengaruh positif terhadap prestasi belajar siswa kelas VIII MTsN 3 Ponorogo. Prestasi belajar siswa yang belajar dengan bantuan bahan ajar digital interaktif lebih tinggi daripada siswa yang belajar tanpa bantuan bahan ajar digital interaktif. Hasil penelitian Kurniawan (2016) menunjukkan bahwa pembelajaran dengan media pembelajaran menghasilkan prestasi belajar yang lebih baik, karena dengan penggunaan media pembelajaran siswa lebih aktif dalam bertanya dan berdiskusi mengenai materi yang sedang dipelajari. Hal ini diperkuat oleh Gustina, Abu, dan Hamsyah (2016) yang menyatakan bahwa media pembelajaran berbasis multimedia berpengaruh terhadap hasil belajar kognitif siswa karena media pembelajaran berbasis multimedia dapat menyajikan materi secara utuh dan sistematik sehingga lebih mudah dipahami oleh para siswa dan memungkinkan siswa menguasai tujuan pembelajaran yang lebih baik.

Pembelajaran dengan bantuan multimedia lebih efektif dalam meningkatkan prestasi belajar (Gunawan et al., 2015) . Penerapan dan penggunaan bahan ajar digital interaktif sangat mendukung pembelajaran yang akan meningkatkan prestasi belajar siswa, karena bahan ajar ini dapat memvisualisasikan materi dengan jelas melalui gambar, video, dan animasi, didesain secara menarik, dan dapat berinteraksi dengan siswa. Penggunaan media pembelajaran dapat merubah pemikiran siswa tentang materi yang abstrak menjadi lebih konkrit. Sebagai contoh siswa dapat mengamati proses perjalanan sinar pada cermin maupun lensa. Dengan demikian siswa dapat meningkatkan kemampuannya dalam memahami materi yang disajikan. Sesuai dengan hasil penelitian Sukiyasa dan Sukoco (2013) yang menunjukkan bahwa proses pembelajaran dengan menggunakan media pembelajaran dapat memberikan kemudahan pemahaman siswa, sehingga mampu meningkatkan pencapaian hasil belajar siswa. Beberapa peneliti juga menekankan bahwa penggunaan media pembelajaran efektif meningkatkan prestasi belajar siswa (Gustina et al., 2016; Izzudin et al., 2013; Ramadhani et al., 2016; Viajayani et al., 2013).

Melalui penggunaan media pembelajaran siswa lebih banyak melakukan kegiatan belajar seperti berinteraksi dengan media dan kegiatan lainnya sehingga siswa tidak merasa bosan. Hal ini diperkuat dengan penerapan model discovery learning dalam proses pembelajaran siswa. Sesuai dengan hasil penelitian Hayati, Bintari, dan Sukaesih (2018), penggunaan model guided-discovery dapat meningkatkan ketrampilan sains terutama dalam kegiatan mengamati. Bahan ajar digital interaktif membuat siswa bisa lebih aktif melakukan pengamatan terkait hal-hal yang abstrak bagi mereka. Selain itu pembelajaran discovery meningkatkan aktivitas bertanya dan berdiskusi terkait materi yang dipelajari. Hal tersebut diperkuat pendapat oleh Wahjudi, (2015) bahwa pembelajaran discovery learning akan meningkatkan aktivitas siswa dalam belajar baik secara individu maupun kelompok. Kristin, (2016) juga menyatakan bahwa discovery learning dapat membangun pengetahuan berdasarkan pengetahuan awal yang dimiliki oleh siswa sehingga siswa nantinya dapat memiliki pemahaman yang lebih mendalam. Pembelajaran discovery learning dapat meningkatkan hasil belajar siswa karena pembelajaran berpusta pada siswa sehingga siswa aktif, tidak jenuh dalam pembelajaran (Hayati et al., 2018); Wahjudi, 2015; Kristin, 2016). 


\section{SIMPULAN DAN SARAN}

\section{Simpulan}

Berdasarkan hasil penelitian yang telah dilakukan dapat disimpulkan bahwa penggunaan bahan ajar digital interaktif dalam pembelajaran IPA dengan model discovery learning berpengaruh positif terhadap prestasi belajar siswa kelas VIII MTsN 3 Ponorogo. Bahan ajar digital interaktif dengan model discovery learning dapat meningkatkan prestasi belajar siswa dalam pembelajaran IPA. Dengan demikian, penggunaan bahan ajar digital interaktif dengan model discovery learning bisa digunakan oleh guru untuk mengakomodasi kemampuan kognitif siswa sehingga prestasi belajar siswa dapat meningkat.

\section{Saran}

Saran yang dapat dipertimbangkan untuk menindaklanjuti penelitian ini antara lain: 1) perlu dilakukan uji efektivitas terhadap bahan ajar digital interaktif. 2) penggunaan bahan ajar interaktif untuk meningkatkan kemampuan berpikir siswa agar mencapai kemampuan berpikir tingkat tinggi sesuai dengan kurikulum 2013 melalui bahan ajar digital interaktif.

\section{DAFTAR PUSTAKA}

Anjarwati, D., Winarno, A., \& Churiyah, M. (2016). Improving learning outcomes by developing instructional media-based Adobe Flash Professional CS 5.5 on principles of business subject. IOSR Journal of Research \& Method in Education, 6(5), 1-6. https://doi.org/10.9790/7388-0605010106

Anwariningsih, S. H., \& Ernawati, S. (2013). Development of interactive media for ICT learning at elementary school based on student self learning. Journal of Education and Learning, 7(2), 121. https://doi.org/10.11591/edulearn.v7i2.226

Busyaeri, A., Udin, T., \& Zaenuddin, A. (2016). Pengaruh penggunaan video pembelajaran terhadap peningkatan hasil belajar mapel IPA di MIN Kroyo Cirebon. Al Ibtida, 3(1), 116-137. Retrieved from http://syekhnurjati.ac.id/jurnal/index.php/ibtida/article/ view/584

Chien, C.-H., Chen, C.-H., \& Jeng, T.-S. (2010). An interactive augmented reality system for learning anatomy structure. International Multi Conference of Engineers and Computer Scientists, 1, 6. https://doi.org/10.1007/978-3-642-10470-1_18

Dewi, S. R., Nurmilawati, M., \& Budiretnani, D. A. (2017). Improving of scientific literacy ability using discovery learning model at the seventh grade students of state JHS 3 Ngronggot, Nganjuk-Indonesia. JPBI (Jurnal Pendidikan Biologi Indonesia), 3(3), 266271. https://doi.org/10.22219/jpbi.v3i3.4597

Djamarah, \& Zain, A. (2002). Strategi Belajar Mengajar. Jakarta: Rineka Cipta.

Druckman, D., \& Ebner, N. (2017). Discovery learning in management education : design and case analysis. Journal of Manajement Education, O(0), 1-28. https://doi.org/10.1177/1052562917720710

Fadhashar, R., Indriyanti, D. R., \& Lisdiana. (2017). Penerapan model guided note taking dengan video pada pembelajaran sistem saraf di SMP. Journal of Biology Education, 6(1), 19-25. https://doi.org/10.15294/jbe.v6i1.13974

Firdaus, S., Damiri, D. J., \& Tresnawati, D. (2012). Perancangan aplikasi multimedia 
interaktif company profile generic. Jurnal Algoritma, 1(9), 1-10. Retrieved from http://sttgarut.ac.id/jurnal/index.php/algoritma/article/view/10

Fitri, M., \& Derlina. (2015). Pengaruh model pembelajaran discovery learning terhadap hasil belajar siswa pada materi pokok suhu dan kalor. INPAFI Inovasi Pembelajaran Fisika, 3(2). https://doi.org/10.24114/inpafi.v3i2.5130

Gunawan, Harjono, A., \& Sutrio. (2015). Multimedia interaktif dalam pembelajaran konsep listrik bagi calon guru. Jurnal Pendidikan Fisika Dan Teknologi, I(1). https://doi.org/10.29303/jpft.v1i1.230

Gustina, Abu, S. H. N., \& Hamsyah, E. F. (2016). Pengaruh penggunaan media pembelajaran berbasis macromedia flash 8 terhadap motivasi dan hasil belajar kognitif siswa kelas VII SMPN 18 Makassar studi pada materi pokok asam, basa dan garam. Jurnal Chemica, 17(2), 12-18. https://doi.org/10.26858/chemica.v17i2.4680

Hakim, A. R., \& Windayana, H. (2016). Pengaruh penggunaan multimedia interaktif dalam pembelajaran matematika untuk meningkatkan hasil belajar siswa SD. EduHumaniora | Jurnal Pendidikan Dasar Kampus Cibiru, 4(2). https://doi.org/10.17509/eh.v4i2.2827

Harsono, B., Soesanto, \& Samsudi. (2009). Perbedaan hasil belajar antara motode ceramah konvensional dengan ceramah berbantuan media animasi pada pembelajaran kompetensi perakitan dan pemasangan sistem rem. Jurnal PTM, 9(2). Retrieved from https://journal.unnes.ac.id/nju/index.php/JPTM/article/view/202

Hayati, D. P., Bintari, S. H., \& Sukaesih, S. (2018). Implementation of the practicum methods with guided-discovery model to the student skill of science process. Journal of Biology Education, 7(1), 118-126. https://doi.org/10.15294/jbe.v7i1.23005

Hayati, N., \& Berlianti, N. A. (2016). Peningkatan aktivitas dan hasil belajar mahasiswa universitas hasyim asy'ari melalui pembelajaran discovery terbimbing. JPBI (Jurnal Pendidikan Biologi Indonesia), 2(3), 206-214. https://doi.org/10.22219/jpbi.v2i3.3857

Hayati, S., Budi, A. S., \& Handoko, E. (2015). Pengembangan media pembelajaran flipbook fisika untuk meningkatkan hasil belajar peserta didik. Prosiding Seminar Nasional Fisika, 4, 49-54. Retrieved from journal.unj.ac.id/unj/index.php/prosidingsnf/article/ download/4810/3587

Husein, S., Herayanti, L., \& Gunawan. (2015). Pengaruh penggunaan multimedia interaktif terhadap penguasaan konsep dan keterampilan berpikir kritis siswa pada materi suhu dan kalor. Jurnal Pendidikan Fisika Dan Teknologi, I(3). https://doi.org/10.29303/jpft.v1i3.262

Iwantara, I. W., Sadia, I. W., \& Suma, I. K. (2014). Pengaruh penggunaan media video youtube dalam pembelajaran IPA terhadap motivasi belajar dan pemahaman konsep siswa. Jurnal Pendidikan Dan Pembelajaran IPA Indonesia, 4(1). Retrieved from http://oldpasca.undiksha.ac.id/e-journal/index.php/jurnal_ipa/article/view/1081

Izzudin, A. M., Masugino, \& Suharmanto, A. (2013). Efektifitas penggunaan media pembelajaran video interaktif untuk meningkatkan hasil belajar praktik service engine dan komponen-komponennya. Automotive Science and Education Journal, 2(2). Retrieved from https://journal.unnes.ac.id/sju/index.php/asej/article/view/1910

Kementerian pendidikan dan kebudayaan. (2016). Standar proses pendidikan dasar dan menengah. Jakarta: Kemendikbud. 
Kristin, F. (2016). Analisis model pembelajaran discovery learning dalam meningkatkan hasil belajar siswa SD. Jurnal Pendidikan Dasar PerKhasa, 2(1), 90-98. https://doi.org/10.31932/jpdp.v2i1.25

Kurniawan, T. D., \& Triharsiwi, T. (2016). Pengaruh penggunaan media video pembelajaran terhadap prestasi belajar ilmu pengetahuan sosial siswa kelas V SD se-kecamatan Gedangsari Gunungkidul tahun ajaran 2015/2016. Trihayu: Jurnal Pendidikan Ke-SDAn, 3(1), 21-26. https://doi.org/10.30738/trihayu.v3i1.739

Kurniawati, I. D., \& Nita, S. (2018). Media pembelajaran berbasis multimedia interaktif untuk meningkatkan pemahaman konsep mahasiswa. DOUBLECLICK: Journal of Computer $\begin{array}{llll}\text { and Information } & \text { Technology, }\end{array}$ https://doi.org/10.25273/doubleclick.v1i2.1540

Leow, M. F. (2014). Interactive multimedia learning: Innovating classroom education in a Malaysian University. The Turkish Online Journal of Educational Technology, 13(2), 99-110. Retrieved from http://www.tojet.net/articles/v13i2/13211.pdf

Lin, C.-S., \& Wu, R. Y.-W. (2016). Effects of web-based creative thinking teaching on students' creativity and learning outcome. EURASIA Journal of Mathematics, Science \& Technology Education, 12(6), 1675-1684. https://doi.org/10.12973/eurasia.2016.1558a

Muhson, A. (2010). Pengembangan media pembelajaran berbasis tekonologi informasi. Jurnal Pendidikan Akuntansi Indonesia, 8(2), 1-10. https://doi.org/10.21831/jpai.v8i2.949

Nurwahidah, I. (2018). Pengembangan soal penalaran model TIMSS untuk mengukur high order thinking (HOT). Thabiea: Journal of Natural ScienceTeaching, 1(1), 20-29. https://doi.org/10.21043/thabiea.v1i1.3874

Oyedele, V., Rwambiwa, J., \& Mamvuto, A. (2013). Using educational media and technology in teaching and learning processes: A case of trainee teachers at Africa University. Academic Research International, 4(1). Retrieved from http://www.savap.org.pk/journals/ARInt./Vol.4(1)/2013(4.1-30).pdf

Purwono, J., Yutmini, S., \& Anitah, S. (2014). Penggunaan media audio-visual pada mata pelajaran Ilmu Pengetahuan Alam di Sekolah Menengah Pertama Negeri 1. Jurnal Teknologi Pendidikan Dan Pembelajaran, 2(2), 18. Retrieved from https://www.jurnal.fkip.uns.ac.id/index.php/tp/article/viewFile/3659/2560

Ramadhani, D. G., Mulyani, B., \& Utomo, B. (2016). Pengaruh penggunaan media mobile learning berbasis android dan LKS dalam model pembelajaran student team achivement division (STAD) terhadap prestasi belajar ditinjau dari kemampuan memori pada materi pokok sistem koloid kelas XI SMA Negeri 2 Purwokerto t. Jurnal Pendidikan Kimia $(J P K), \quad 5(4), \quad 16-25 . \quad$ Retrieved from https://jurnal.fkip.uns.ac.id/index.php/kimia/article/view/9019/6917

Sudjana, N., \& Rivai, A. (2011). Media Pengajaran. Sinar Baru Algensindo.

Sukiyasa, K., \& Sukoco. (2013). Pengaruh media animasi terhadap hasil belajar dan motivasi belajar materi sistem kelistrikan otomotif. Jurnal Pendidikan Vokasi, 3, 126-137. https://doi.org/10.21831/jpv.v3i1.1588

Supriyanto, B. (2014). Penerapan discovery learning untuk meningkatkan hasil belajar siswa kelas VI B mata pelajaran matematika pokok bahasan keliling dan luas lingkaran di SDN Tanggul Wetan 02 Kecamatan Tanggul Kabupaten Jember. Pancaran Pendidikan, 3(2), 
165-167. Retrieved from https://jurnal.unej.ac.id/index.php/pancaran/article/view/753

Suradnya, L. S. A., Suyanto, E., \& Suana, W. (2016). Modul interaktif dengan program LCDS untuk materi cahaya dan alat optik. Jurnal Pembelajaran Fisika, 4(2), 35-46. Retrieved from http://jurnal.fkip.unila.ac.id/index.php/JPF/article/view/11073

Sutarno. (2011). Penggunaan multimedia interaktif pada pembelajaran medan magnet untuk meningkatkan keterampilan generik sains mahasiswa. Jurnal Exacta, IX(1), 60-66. Retrieved from http://repository.unib.ac.id/1088/

Viajayani, E. R., Radiyono, Y., \& Rahardjo, D. T. (2013). Pengembangan media pembelajaran fisika menggunakan macromedia flash pro 8 pada pokok bahasan suhu dan kalor. Jurnal Pendidikan Fisika, 1(1), 144-155. Retrieved from https://jurnal.fkip.uns.ac.id/index.php/pfisika/article/view/1774

Wahjudi, E. (2015). Penerapan discovery learning dalam pembelajaran IPA sebagai upaya untuk meningkatkan hasil belajar siswa kelas IX-I di SMP Negeri 1 Kalianget. LENSA (Lentera Sains): Jurnal Pendidikan IPA, 5(1), 1-16. https://doi.org/10.24929/fkip.v5i1.242

Wardani, S., Mudzalipah, I., \& Hidayat, E. (2013). Pengembangan media pembelajaran berbasis multimedia interaktif untuk memfasilitasi belajar mandiri mahasiswa pada mata kuliah kapita selekta matematika. Jurnal Pengajaran MIPA, 18(2), 167-177. https://doi.org/10.18269/jpmipa.v18i2.7

Widiyawati, Y. (2017). Pemanfaatan media pembelajaran IPA bagi peserta didik visual impairment di SLB. JIPVA (Jurnal Pendidikan IPA Veteran), 1(1), 9-23. Retrieved from http://e-journal.ivet.ac.id/index.php/jipva/article/view/510

\section{PROFIL SINGKAT}

Ngulmi Khamidah lahir di Ponorogo pada tanggal 19 Mei 1996. Menempuh pendidikan sarjada di Universitas Negeri Malang, Fakultas Matematika dan Ilmu Pengetahuan Alam (FMIPA) mengambil program studi Pendidikan IPA lulus pada tahun 2019.

Drs. Winarto, M.Pd. Lahir pada tanggal 10 Juni 1957. Pendidikan S1 ditempuh di program studi pendidikan Fisika IKIP Malang lulus pada tahun 1989 dan pendidikan S2 ditempuh di program studi pendidikan Fisika Universitas Negrei Malang lulus pada tahun 2013. Kini aktif mengajar di program studi pendidikan Fisika Universitas Negeri Malang.

Vita Ria Mustika Sari, S.Pd., M.Pd. Lahir pada tanggal 30 April 1986. Pendidikan S1 ditempuh di program studi pendidikan Fisika Universitas Negeri Malang lulus pada tahun 2008 dan pendidikan S2 ditempuh di program studi pendidikan Fisika Universitas Negeri Malang lulus pada tahun 2013. Kini aktif mengajar di program studi pendidikan IPA Universitas Negeri Malang. 